\title{
Crystallization and Mechanical Properties of Polypropylene under Processing-Relevant Cooling Conditions with respect to Isothermal Holding Time
}

\author{
Christopher Fischer and Dietmar Drummer \\ Institute of Polymer Technology, Friedrich-Alexander University of Erlangen-Nürnberg, 91058 Erlangen, Germany \\ Correspondence should be addressed to Christopher Fischer; fischerc@lkt.uni-erlangen.de
}

Received 1 June 2016; Revised 26 July 2016; Accepted 17 August 2016

Academic Editor: Maria Laura Di Lorenzo

Copyright (C) 2016 C. Fischer and D. Drummer. This is an open access article distributed under the Creative Commons Attribution License, which permits unrestricted use, distribution, and reproduction in any medium, provided the original work is properly cited.

\begin{abstract}
For semicrystalline thermoplastics, aside from pressure and shear, the temperature-time behavior while cooling the melt significantly affects the geometry and degree of ordered structures (e.g., spherulite size, degree of crystallization, and crystal modification) and, as a consequence, the resulting global component properties. Previous research has shown that a higher isothermal holding temperature (e.g., mold temperature and chill-roll temperature) leads to the formation of more distinct ordered structures and, therefore, can lead to greater stiffness and strength. Nevertheless, isothermal holding time during manufacturing is typically not taken into account. In this paper, fast scanning calorimetry (FSC) measurements were taken using polypropylene to analyze the crystallization during idealized temperature-time profiles based on the dynamic temperature process and to investigate the crystallization behavior at different temperatures and isothermal holding times analytically. Furthermore, iPP foils were extruded and tested mechanically to investigate the knowledge gained experimentally. Analytical and mechanical results show that foils produced at the same isothermal holding temperature can obtain significantly different ordered structures and mechanical properties depending primarily on the isothermal holding time.
\end{abstract}

\section{Introduction}

For semicrystalline thermoplastics it is known that crystalline and amorphous areas typically arrange into spherulitic superstructures during the crystallization process especially under quiescent conditions [1]. Next to pressure and shearing, the temperature-time behavior while cooling a polymer mainly influences the formation of the geometry and degree of ordered structures (e.g., crystal modification, spherulite size, and degree of crystallization) since the crystallization process with its nucleation and crystal growth phase takes place at that time $[2,3]$. Due to a low nucleation rate and relatively high crystal growth rate the morphology develops coarsely and distinctly for higher isothermal holding temperatures $T_{h}$ (e.g., mold temperature for injection molding and chill-roll temperature for extrusion). With increasing cooling velocity the spherulites become smaller in diameter and the morphology looks more finely distinct up to optically amorphous, since crystal growth is hindered due to a large number of nuclei caused by high thermal nucleation [2-4]. Various forms of previous research have investigated the influence cooling velocity has on the resulting degree of crystallization (amount of the crystalline fraction) for semicrystalline thermoplastics. An increase in cooling velocity can lead to a decrease in the resulting degree of crystallization and by exceeding a critical cooling velocity the melt can solidify amorphously [4-7]. Next to affecting the degree of crystallization, the great majority of semicrystalline thermoplastics can crystallize in different crystal modifications [7-12] depending, for example, on the cooling velocity. Regarding isotactic polypropylene primary four different polymorphs are discussed in the literature: $\alpha$-phase, $\beta$-phase, $\gamma$-phase, and a mesomorphic phase [13]. Here, $\beta$ - and $\gamma$-crystals primarily form under certain conditions such as specific nucleating agents or shear-stress during manufacturing $[14,15]$ (for $\beta$ form) and elevated pressure (for $\gamma$-form) [16]. The most 
stable form is discussed to be the monoclinic $\alpha$-form, which develops when cooling the melt with low to moderate cooling conditions in a temperature range from $50^{\circ} \mathrm{C}$ to $T_{m}$ [17]. At temperatures less than or equal to $50^{\circ} \mathrm{C}$ the mesomorphic phase occurs. Brucato et al. [18, 19] asserts that, with an increasing cooling velocity, the amount of the mesomorphic phase increases and the density decreases. With a special focus on the crystalline structure and morphology with respect to the cooling rate Piccarolo et al. [20,21] described the formation of the mesomorphic phase with isolated, negatively birefringent spherulites for cooling rates greater than $80 \mathrm{~K} / \mathrm{s}$. For cooling rates between 20 and $80 \mathrm{~K} / \mathrm{s}$ mesomorphic and $\alpha$-monoclinic phases coexist with negatively birefringent spherulites surrounded by a weakly birefringent medium. For cooling rates lower than $20 \mathrm{~K} / \mathrm{s}$ primarily $\alpha$ form with impinging spherulites is observed. Further detailed information about the polymorphism and morphologies with a particular focus on the mesomorphic phase of isotactic polypropylene (iPP) is summarized in Androsch et al. [22].

To assess resulting component properties (e.g., mechanical properties and tribological properties), the influence different cooling velocities have on the formation of crystalline and structural properties needs to be considered since they are mainly responsible for the resulting component properties. Here, the effects can hardly be explained with a single structural effect since changing one inner structural property normally leads to a change in the other properties as well (e.g., a change in spherulitic structure often accompanies a change in the degree of crystallization). Keeping this in mind, various works were able to show that increasing the degree of crystallization can increase the stiffness as well as strength and decrease elongation at break [23]. Furthermore, a distinctly fine spherulitic morphology can show higher strength and elongation at break than a coarsely distinct spherulitic morphology $[2,24]$. Regarding different crystal modifications, for example, for PA 6, Kolesov et al. [11] estimated the differences in the storage modulus in the chain direction from 300-310 to 50-140 GPa for $\alpha$ and $\gamma$, respectively.

In general, regarding the temperature-time behavior of a thermoplastic component during the manufacturing process, for a variety of conventional manufacturing technologies (e.g., injection molding and extrusion) the material's cooling condition is the result of the processing parameters chosen beforehand (e.g., chill-roll temperature, mold temperature, material's melt temperature, and component wall thickness). Considering conventional injection molding and, therefore, a greater wall thickness, current research describes cooling velocities of about $1000 \mathrm{~K} / \mathrm{s}$ regarding the skin near component area while in the core area values of about $1 \mathrm{~K} / \mathrm{s}$ are estimated $[25,26]$. In the literature the influence of mold temperature on the formation of the geometry and degree of ordered structures and the resulting component properties are often discussed from an application-oriented view. For example, using a higher mold temperature can lead to less wear and greater stiffness [24]. Nevertheless, at dynamic tempering the importance of isothermal holding time $t_{h}$ during manufacturing is normally not taken into account. Therefore, it is the aim of this paper to show the influence

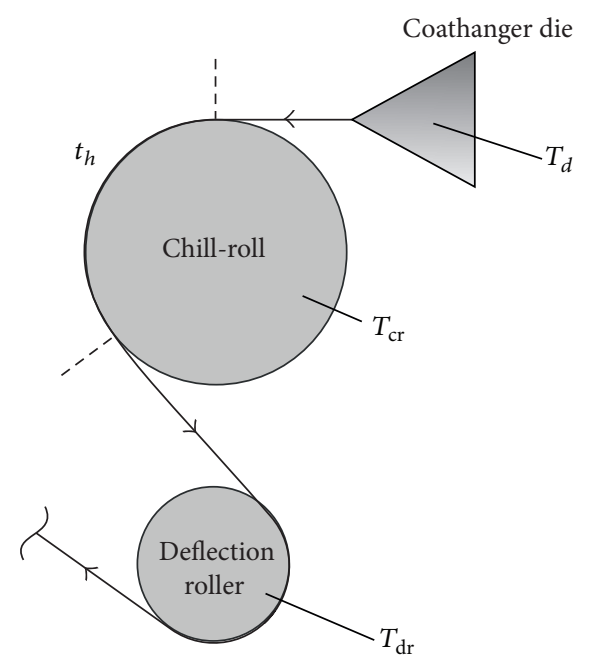

FIGURE 1: Schematical illustration of isothermal holding time during flat film extrusion $\left(t_{h}=\right.$ isothermal holding time, $T_{\mathrm{cr}}=$ chill-roll temperature, $T_{d}=$ die temperature, and $T_{\mathrm{dr}}=$ deflection roller temperature).

of $t_{h}$ at different mold temperatures, particularly chill-roll temperatures (Figure 1), analytically and experimentally with the help of fast scanning calorimetry and flat film extrusion.

\section{Materials and Methods}

2.1. Material and Test Specimens. For this research, iPP (Sabic 505P), supplied by SABIC, was used. According to the datasheet this PP-type is a homopolymer with medium isotacticity and a melt flow rate of $2 \mathrm{dg} / \mathrm{min}$. For the tensile tests, tensile bars were prepared from the extruded foils along the extrusion direction. The geometry was derived from the Campus tensile bar according to DIN EN ISO 527-2B with a scaling of 1:4. Regarding the dynamic-mechanical analyses, rectangular samples with a width of $1 \mathrm{~mm}$ and a length of $8 \mathrm{~mm}$ were prepared from the extruded foil along the extrusion direction.

2.2. Fast Scanning Calorimetry (FSC). The FSC measurements were taken using a Flash DSC 1 by Mettler-Toledo. For that purpose, a test sample was prepared from a $10 \mu \mathrm{m}$ thin cut using a scalpel and placed on the measuring sensor area of the FSC. For all tests one test sample was used and, therefore, the same sample mass was used for all tests. For depicting the results, the measured heat flow rate was illustrated with respect to temperature. In order to verify that there are no ageing effects comparison measurements were repeated at the end of all measurements, which showed the exact same crystallization effects.

For a better understanding of the process-based crystallization with focus on evaluation of $t_{h}$ first the crystallization at different cooling velocities is examined. Here, different cooling velocities were analyzed in the range of 1 to $2000 \mathrm{~K} / \mathrm{s}$. Therefore, the sample first was heated up to $250^{\circ} \mathrm{C}$ and then cooled down to $-20^{\circ} \mathrm{C}$ with the respective cooling velocity. The second heating was chosen with $500 \mathrm{~K} / \mathrm{s}$. This heating 
TABLE 1: Temperature-time profiles analyzed by FSC.

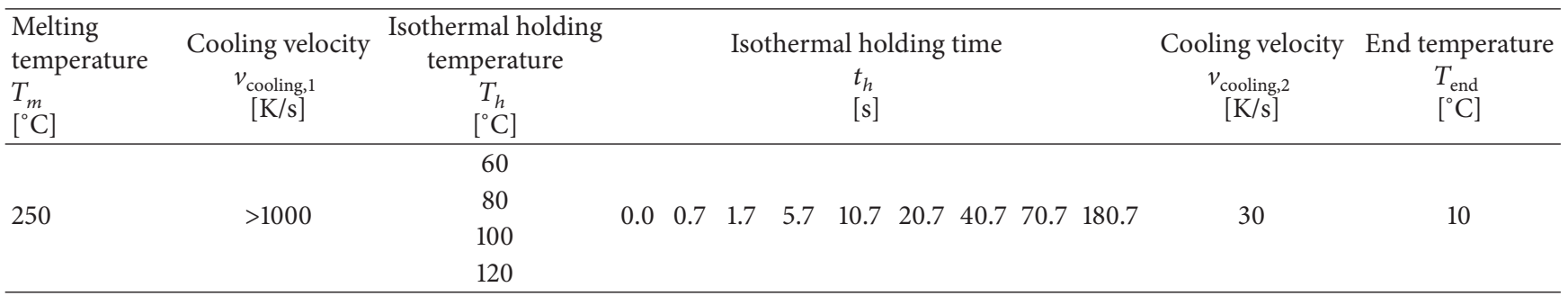

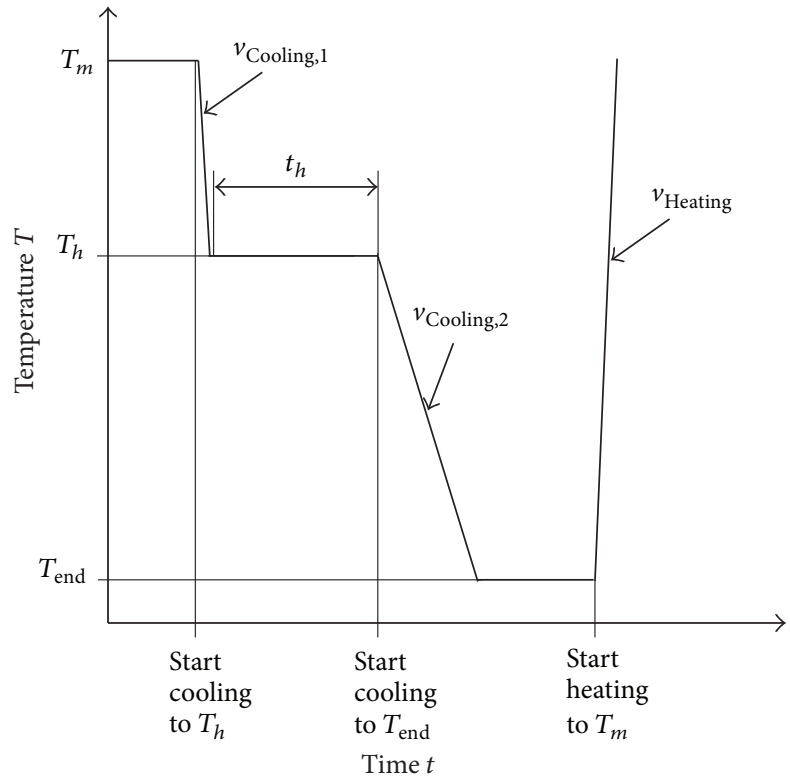

FIGURE 2: Simplified temperature-time profile during cooling derived from the conventional manufacturing cooling step with subsequent heating analyzed by FSC $\left(t_{H}=\right.$ isothermal holding time, $T_{\text {end }}=$ end temperature, $T_{h}=$ isothermal holding temperature, $T_{m}=$ melting temperature, $v_{\text {Cooling }}=$ cooling velocity, and $v_{\text {Heating }}=$ heating velocity).

velocity was determined in preliminary investigations and was recommended to evaluate the melting behavior of iPP since here cold crystallization and reorganization effects could be measured in good resolution.

Furthermore, a theoretically based temperature-time profile during cooling, derived from the conventional manufacturing cooling step, was investigated; compare Figure 2. Here, the sample first was heated up to $250^{\circ} \mathrm{C}$ and then cooled down to $T_{h}$ with a cooling velocity $\geq 1000 \mathrm{~K} / \mathrm{s}$, Table 1 . This temperature represents the mold temperature for the dynamically tempered injection molding process during injection, as well as the chill-roll temperature for extrusion. Afterwards, the temperature was held isothermally for a defined $t_{h}$ in the range between 0.0 and 180.7 seconds and then cooled at a cooling velocity of $30 \mathrm{~K} / \mathrm{s}$ to (according to the maximum attainable cooling velocities of modern dynamically tempered injection molds $[27,28]) 10^{\circ} \mathrm{C}$. Again, the second heating was chosen at $500 \mathrm{~K} / \mathrm{s}$.
2.3. Processing. In addition to the analytically based material characterization using FSC, iPP foils were extruded via flat film extrusion using chill-roll casting. For that, a single screw extruder, Collin E30M, with a $30 \mathrm{~mm}$ screw diameter and length/thickness ratio of 25 and a coathanger die of $250 \mathrm{~mm}$ width in combination with the chill-roll Collin CR136/350 were used. The die temperature was set to $250^{\circ} \mathrm{C}$. Foils were produced at a chill-roll temperature of 55, 80, 100, and $120^{\circ} \mathrm{C}$ to investigate the influence of $t_{h}$ under different thermodynamic conditions. Here, the minimum chill-roll temperature, that is, $T_{h}$, was chosen to be greater than $50^{\circ} \mathrm{C}$ to ensure that primary $\alpha$-phase was generated. The deflection roller temperature, which represents the end temperature, was chosen with the lowest possible value of $30^{\circ} \mathrm{C} . t_{h}$ was chosen with $3 \mathrm{~s}$ and $20 \mathrm{~s}$, which represented the minimum and maximum possible time to produce high-quality foils by adjusting the screw rotation speed as well as the haul-off speed. Here, for $3 \mathrm{~s}$ the screw rotation speed and the haul-off speed were set to $50 \mathrm{~min}^{-1}$ and $3.6 \mathrm{~m} / \mathrm{min}$, respectively. For $20 \mathrm{~s}$ the screw rotation speed and the haul-off speed were set to $12 \mathrm{~min}^{-1}$ and $0.59 \mathrm{~m} / \mathrm{min}$, respectively. The foil thickness was set to approximately $100 \mu \mathrm{m}$. During the manufacturing process, the foil temperatures were measured at all relevant positions during the production line with an IR-camera while considering the respective emission coefficients. The derived temperature-time profiles are shown in Figure 3.

\subsection{Investigation Methods regarding the Produced Foils}

Morphology. The cross-section's morphology of the extruded foils was investigated via linearly polarized light microscopy with an Axio Imager.M2 by Zeiss at $10 \mu \mathrm{m}$ thin cuts at under $45^{\circ}$. The cuts were taken from the middle of the foil along the direction of extrusion.

Degree of Crystallization. To calculate the degree of crystallization the melting enthalpy $\Delta H_{m}$ was determined with DSC measurements using a Q 1000 TMDSC by TA Instruments according to DIN EN ISO 11357 and correlated with $\Delta H_{m}^{0}$ (melting enthalpy of $100 \%$ crystalline material) which is described to be $205 \mathrm{~J} / \mathrm{g}$ [29].

Mechanical Parameters. To determine the mechanical parameters tensile tests as well as dynamic-mechanical analyses (DMA) were carried out with specimens prepared from the foil along the extrusion direction. Here, the tensile tests were 


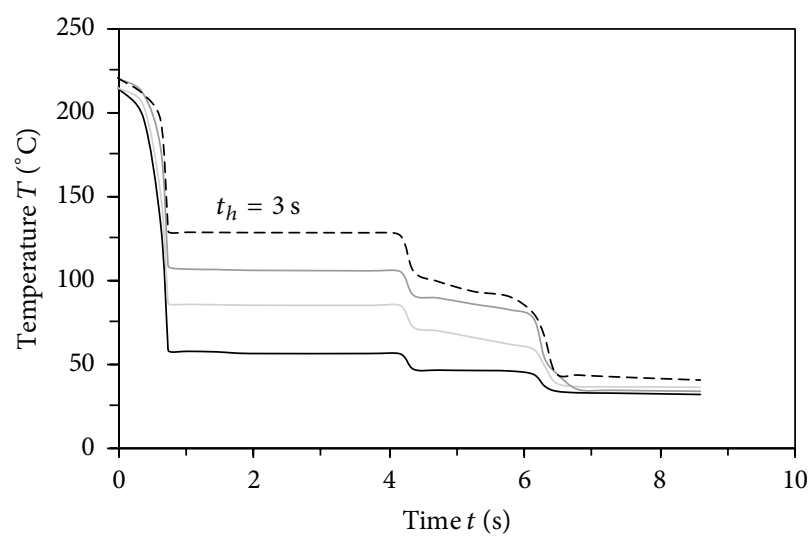

Chill-roll temperature $T_{\mathrm{cr}}=$

$$
\begin{array}{rr}
55^{\circ} \mathrm{C} & -100^{\circ} \mathrm{C} \\
80^{\circ} \mathrm{C} & --120^{\circ} \mathrm{C}
\end{array}
$$

(a)

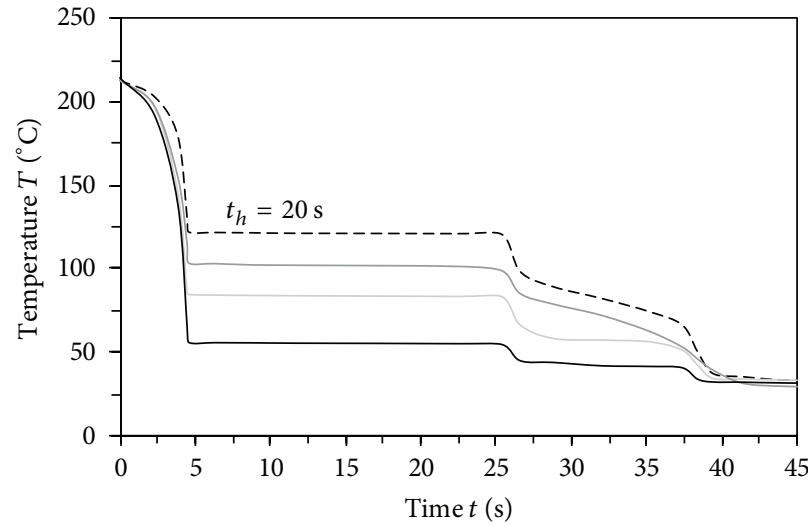

$\begin{array}{ll}\text { Chill-roll temperature } T_{\mathrm{cr}}= & \\ -55^{\circ} \mathrm{C} & 100^{\circ} \mathrm{C} \\ 80^{\circ} \mathrm{C} & ---120^{\circ} \mathrm{C}\end{array}$

(b)

FIGURE 3: Measured temperature-time profile for the extruded foils measured with IR-camera for an isothermal holding time of $3 \mathrm{~s}$ (a) and $20 \mathrm{~s}(\mathrm{~b})$.

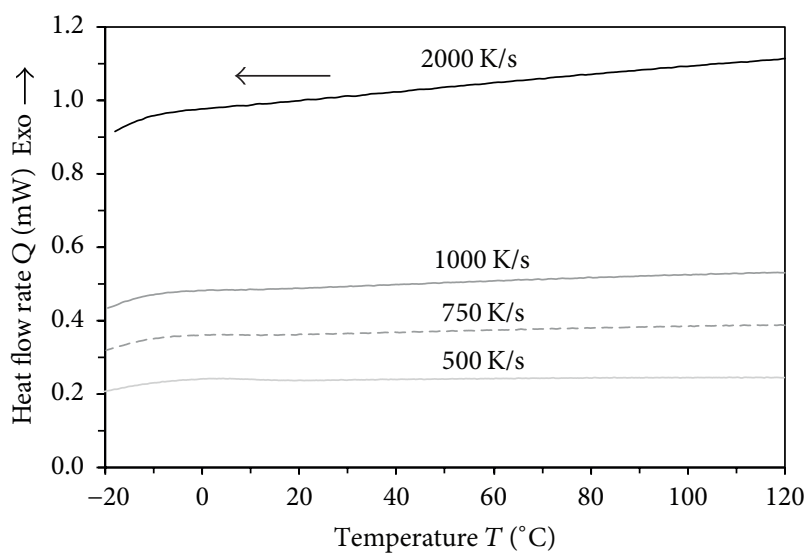

(a)

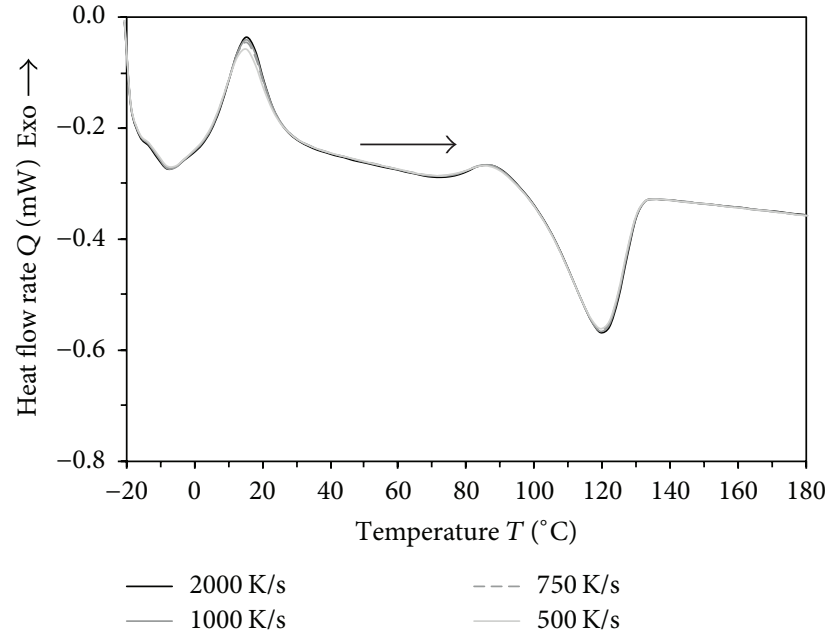

(b)

FIGURE 4: Heat flow rate measured during cooling (a) and second heating (b) of iPP with respect to the examined cooling velocities from 2000 to $500 \mathrm{~K} / \mathrm{s}$.

performed according to DIN EN ISO 527-1 and -3 using a 5948 MicroTester by Instron. As parameters, the secant modulus (ranging from 2 to $10 \mathrm{~N} / \mathrm{mm}^{2}$ ) and the yield stress were determined with 5 test samples. To determine the storage modulus, dynamic-mechanical analyses according to ISO 6721-4 were carried out using an RSA-G2 by TA Instruments. For both investigatory methods (tensile tests and DMA) the samples were conditioned at $23^{\circ} \mathrm{C}$ and $50 \%$ humidity.

\section{Results and Discussion}

\subsection{FSC}

Crystallization with respect to Cooling Velocity. Figures 4 and 5 depict the measured heat flows during cooling and second heating for the investigated cooling velocities from 2000 to $500 \mathrm{~K} / \mathrm{s}$ and 500 to $100 \mathrm{~K} / \mathrm{s}$, respectively. Results correlate well with the results from Schawe [12]. Therefore, during cooling at velocities greater than $300 \mathrm{~K} / \mathrm{s}$ no significant exothermic effects were able to be measured, which leads to the assumption that the majority of the polymer chains solidify amorphously in a glassy state. This is then confirmed in the second heating. Here, at lower temperatures the amorphous structures melt since (between -10 and $10^{\circ} \mathrm{C}$ ) the glass transition temperature was exceeded. At higher temperatures a significant exothermic peak was measured in the range of 10 to $40^{\circ} \mathrm{C}$, which indicates cold crystallization during the heating step. It is assumed that the mesomorphic phase was being formed during this step. By further increasing the 


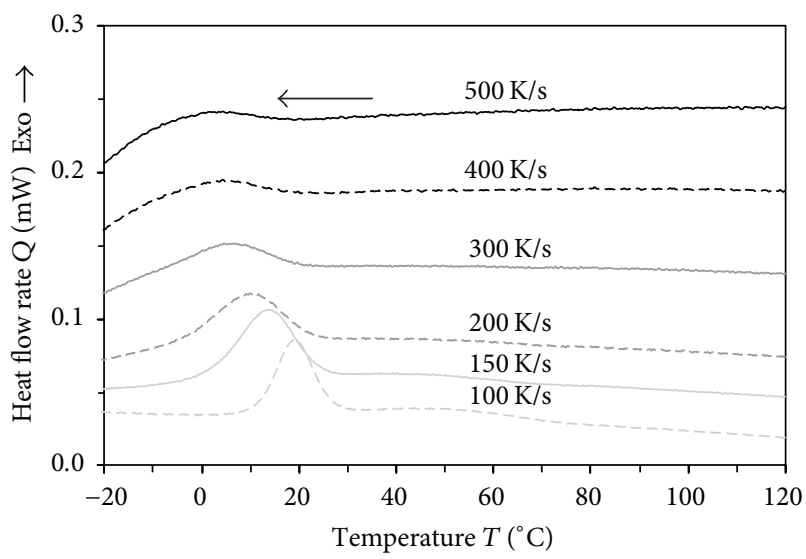

(a)

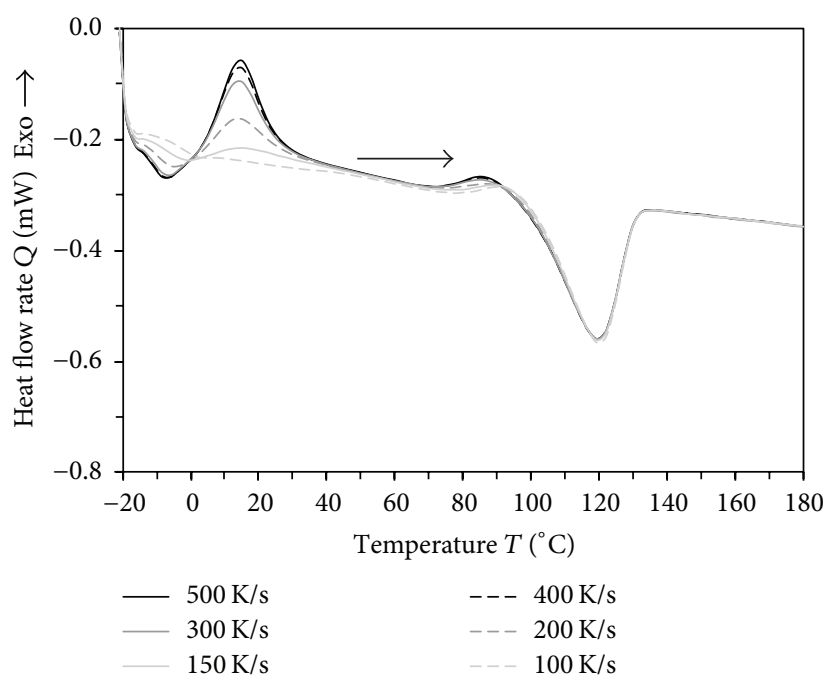

(b)

FIGURE 5: Heat flow rate measured during cooling (a) and second heating (b) of iPP with respect to the examined cooling velocities from 500 to $100 \mathrm{~K} / \mathrm{s}$.

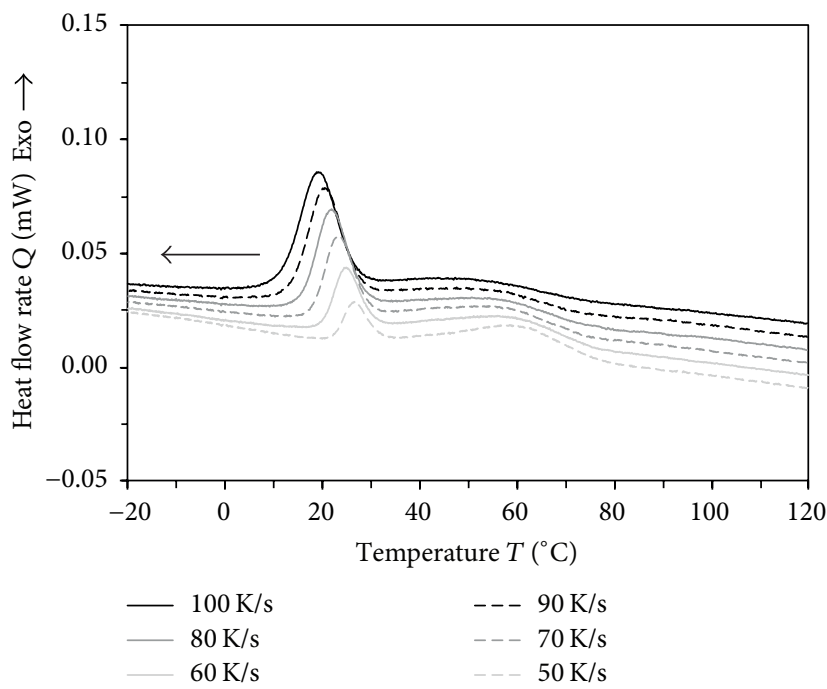

(a)

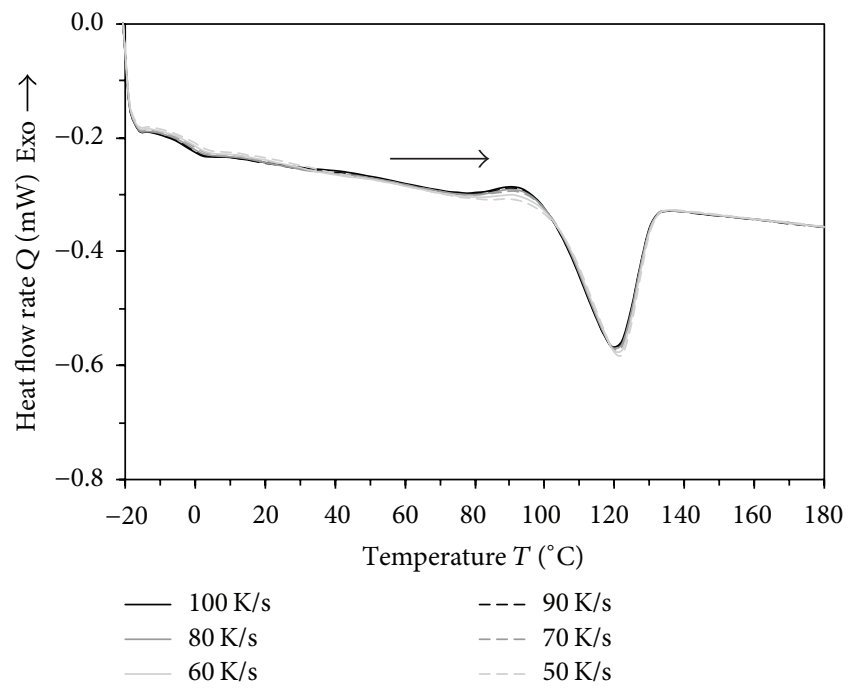

(b)

FIGURE 6: Heat flow rate measured during cooling (a) and second heating (b) of iPP with respect to the examined cooling velocities from 100 to $50 \mathrm{~K} / \mathrm{s}$.

temperature the melting of the mesomorphic phase (between 40 and $80^{\circ} \mathrm{C}$ ) and reorganization into the monoclinic $\alpha$ phase (between 80 and $100^{\circ} \mathrm{C}$ ) assumedly took place. Finally, from 100 to $135^{\circ} \mathrm{C}$, the melting of the $\alpha$-phase takes place. Regarding the different cooling velocities from 2000 to $500 \mathrm{~K} / \mathrm{s}$ no significant differences during cooling and second heating were able to be measured. By further reducing the cooling velocity, in the range from 200 to $300 \mathrm{~K} / \mathrm{s}$, an increase in the exothermal peak's amplitude during cooling and a shift of $T_{\mathrm{pc}}$ towards higher temperatures were measured, which may indicate that crystallization takes place. In addition to the exothermic peak in the range of 0 to $30^{\circ} \mathrm{C}$ for $150 \mathrm{~K} / \mathrm{s}$ and $100 \mathrm{~K} / \mathrm{s}$ the beginning of the formation of an exothermic peak at higher temperatures (between 40 and $60^{\circ} \mathrm{C}$ ) was evident.
Here, it was assumed that $\alpha$-phase emerges. Regarding second heating at previous cooling rates at $300 \mathrm{~K} / \mathrm{s}$, the cold crystallization peak decreases with decreasing cooling velocity, which can also be correlated with a higher amount of the mesomorphic phase. With a decreasing cooling velocity, at values less than or equal to $150 \mathrm{~K} / \mathrm{s}$, the majority of polymer chains were able to crystallize since no significant cold crystallization peak is evident. Furthermore, the decrease in the exothermic shoulder in the range between 80 and $100^{\circ} \mathrm{C}$ with previous cooling velocities less than or equal to $150 \mathrm{~K} / \mathrm{s}$ confirms the assumption that a part of the material had been able to crystallize in $\alpha$-phase during cooling.

Figures 6 and 7 show the measured heat flows during cooling and second heating for the investigated cooling 


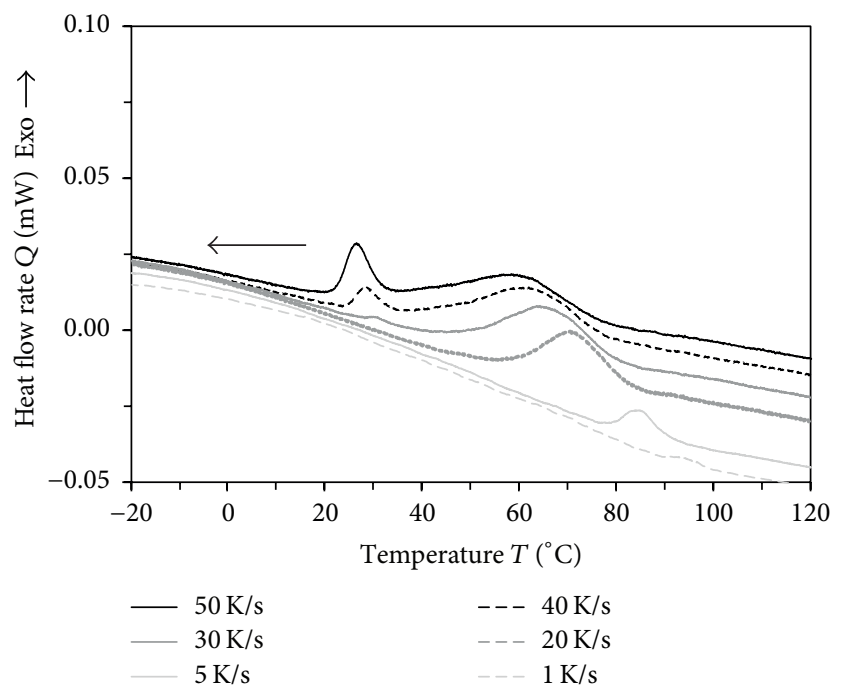

(a)

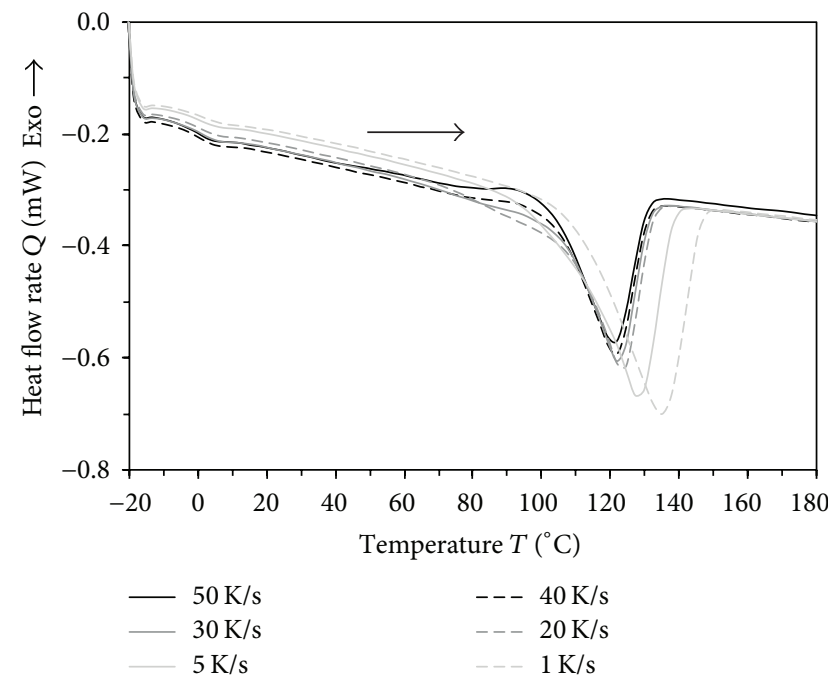

(b)

FIGURE 7: Heat flow rate measured during cooling (a) and second heating (b) of iPP with respect to the examined cooling velocities from 50 to $1 \mathrm{~K} / \mathrm{s}$.

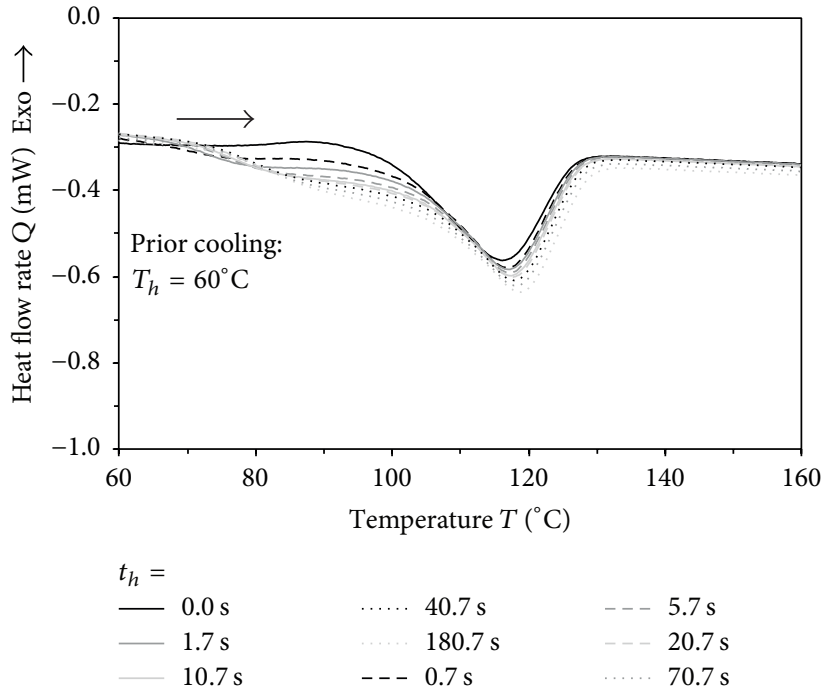

(a)

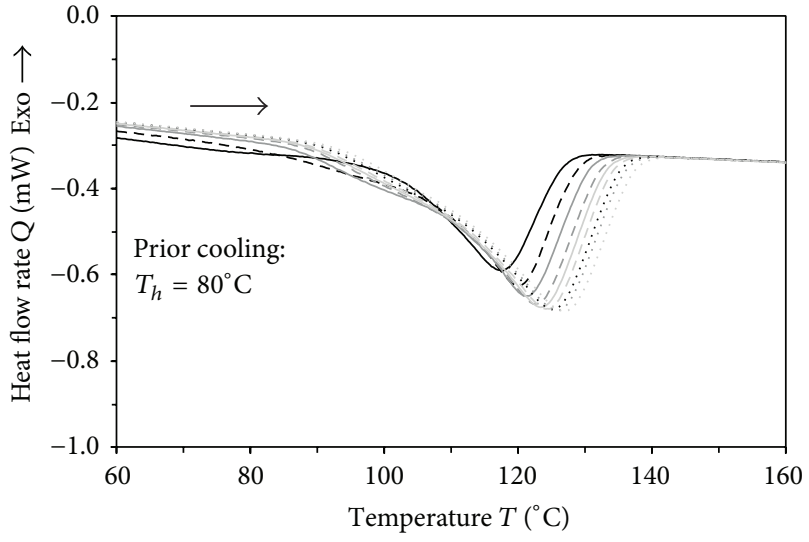

$t_{h}=$
$-0.0 \mathrm{~s}$
$-1.7 \mathrm{~s}$
$-10.7 \mathrm{~s}$

(b)

FIGURE 8: Heat flow rate measured during second heating of process-based cooled samples with isothermal holding step at $60^{\circ} \mathrm{C}(\mathrm{a})$ and $80^{\circ} \mathrm{C}$ (b).

velocities from 100 to $50 \mathrm{~K} / \mathrm{s}$ and 50 to $1 \mathrm{~K} / \mathrm{s}$, respectively. As for the cooling the mesomorphic crystallization peak decreases while the $\alpha$-peak increases. For cooling velocities less than or equal to $20 \mathrm{~K} / \mathrm{s}$ no mesomorphic crystallization was able to be detected. In the second heating a decrease in the exothermal shoulder is measured under decreasing, prior cooling conditions, which also shows the reduction in the mesomorphic phase amount. Furthermore, with prior formation of the $\alpha$-phase (previous cooling velocity $\leq 20 \mathrm{~K} / \mathrm{s}$ ), the melting peak temperature $T_{\mathrm{pm}}$ starts to shift towards higher temperatures, since $\alpha$-structures can form more perfectly.
Crystallization in Theoretically Based Temperature-Time Profiles. Figures 8 and 9 show the second heating of the FSC measurements for the analyzed cooling conditions derived from a conventional manufacturing process. Regarding the effect of $T_{h}$ for 60,80 , and $100^{\circ} \mathrm{C}$ with an increasing $t_{h}$ a shift in the melting peak temperature was found, which shows that either a higher amount of and/or more stable crystals had formed, which can be explained by isothermal crystallization. Here, the melting peak of $t_{h}$ of $180 \mathrm{~s}$ shows different melting behavior with respect to $T_{h}$. Therefore, a higher $T_{h}$ leads to crystal melting at higher temperatures. Furthermore, it can be 

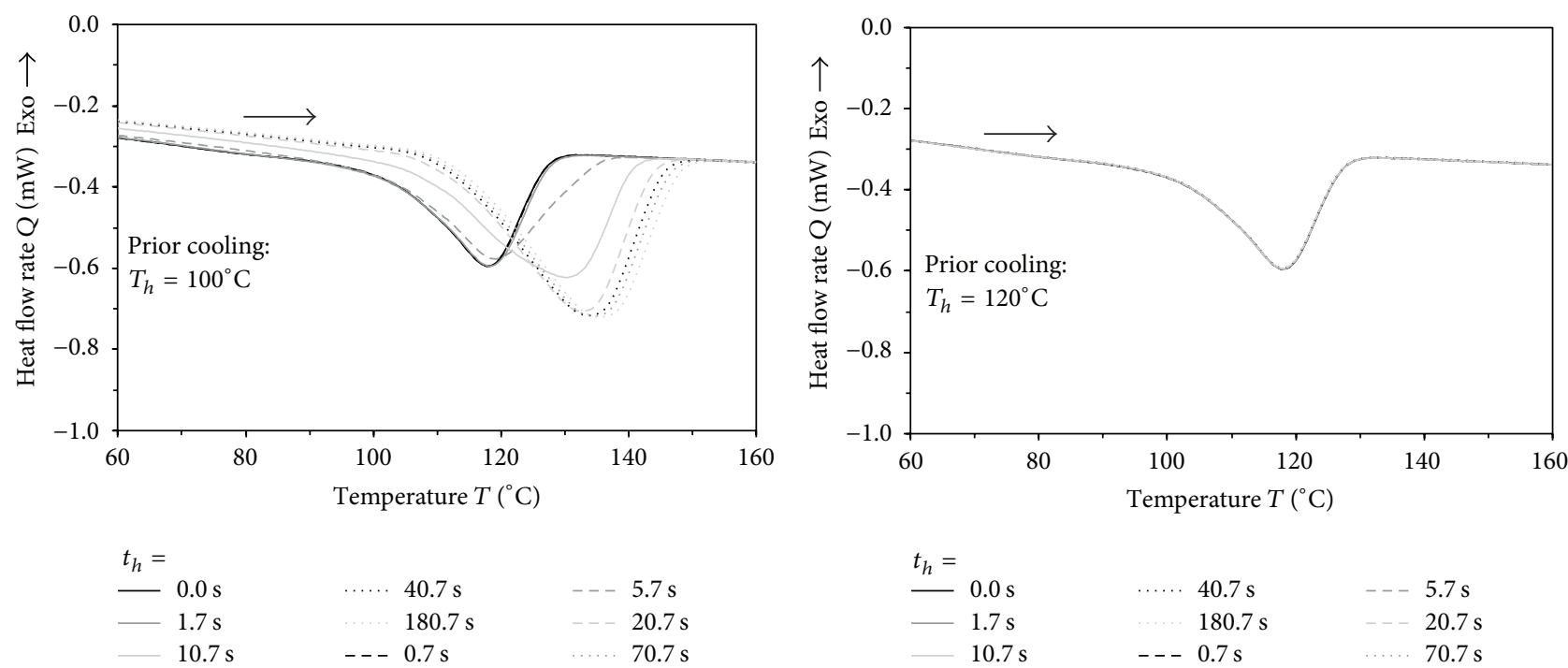

(a)
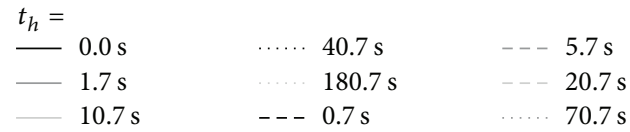

(b)

FIGURE 9: Heat flow rate measured during second heating of process-based cooled samples with isothermal holding step at $100^{\circ} \mathrm{C}(\mathrm{a})$ and $120^{\circ} \mathrm{C}(\mathrm{b})$.

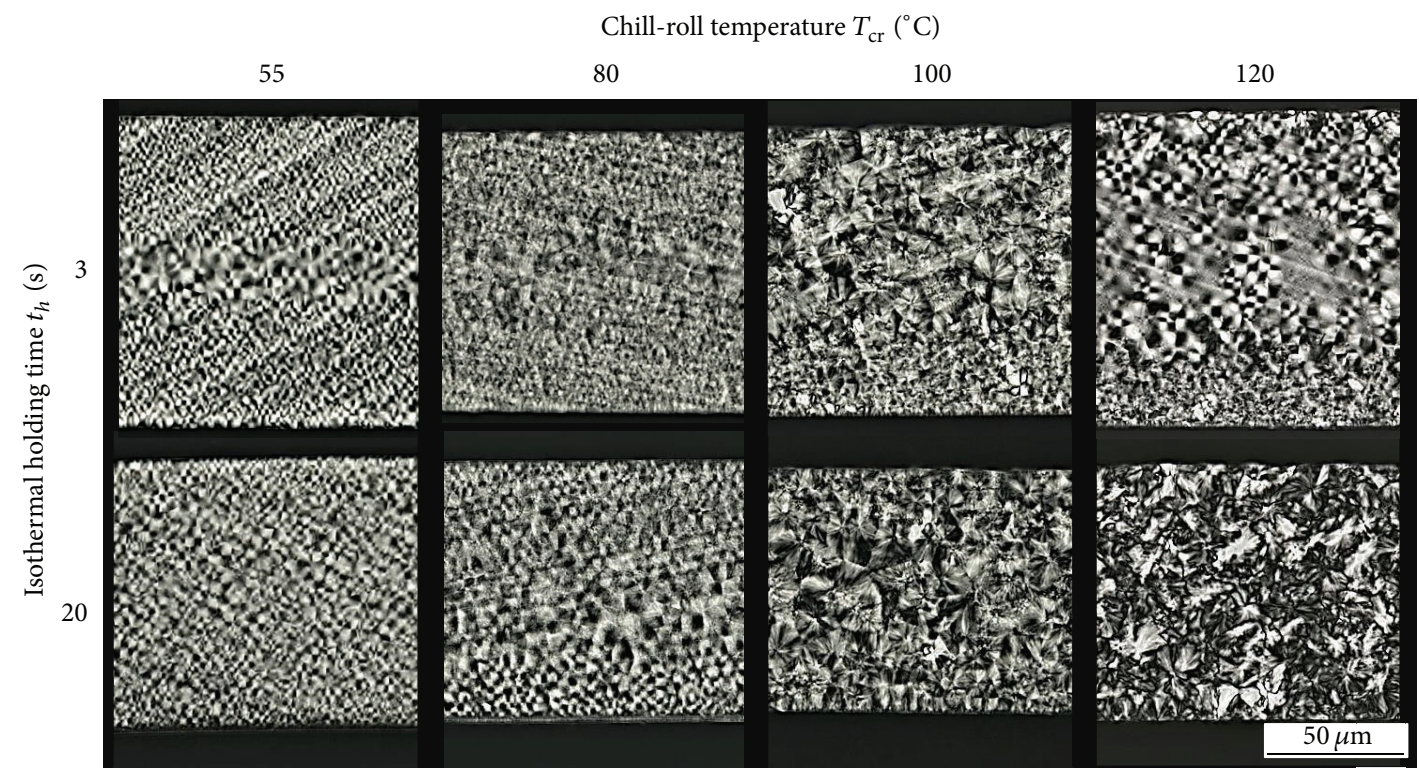

FIGURE 10: Morphology over the cross-section of extruded foils manufactured at different chill-roll temperatures and isothermal holding times.

seen, especially when comparing $80^{\circ} \mathrm{C}$ and $100^{\circ} \mathrm{C}$, that with an increasing $T_{h}$ the duration for isothermal crystallization also increases, which can be explained by the lower undercooling of the melt. At $120^{\circ} \mathrm{C}$ no significant isothermal crystallization was able to be measured. Here, it is assumed that due to the low undercooling of the melt the crystallization kinetics were too low for isothermal crystallization and the main crystallization took place during subsequent cooling with $30 \mathrm{~K} / \mathrm{s}$.

\subsection{Foil Characterization}

Morphology. The resulting morphologies of the extruded foils manufactured at varying $t_{h}$ and chill-roll temperatures
$\left(T_{h}\right)$ are shown in Figure 10. Considering the effect of $T_{h}$ for foils produced at $20 \mathrm{~s} t_{h}$ it can be seen that an increase in temperature led to a significantly more coarsely distinct inner structure. Therefore, the resulting spherulitic structures showed a greater diameter with an increasing $t_{h}$. Comparing the morphology over the entire foil cross-section, the spherulitic structures located in the middle tend to appear more coarsely distinct. This could possibly be explained by shear-induced nuclei in the layer close to the skin due to melt shearing inside the extrusion die. Regarding the effect of an increasing $T_{h}$ for foils produced with $t_{h}$ of $3 \mathrm{~s}$ an increase in the crystalline structure sizes was able to be measured up to $100^{\circ} \mathrm{C}$. Nevertheless, at $120^{\circ} \mathrm{C}$, especially in 


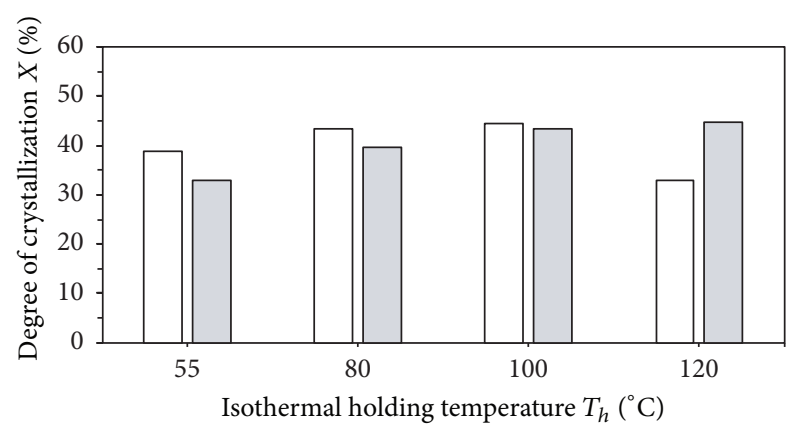

Isothermal holding time $t_{h}=$

- $3 \mathrm{~s}$

口 $20 \mathrm{~s}$

FIGURE 11: Degree of crystallization of extruded foils manufactured at different chill-roll temperatures and isothermal holding times.

the core region, the spherulites appear more finely distinct compared to the spherulitic structures of the foils produced at $100^{\circ} \mathrm{C}$. Here, it is assumed that $t_{h}$ of $3 \mathrm{~s}$ is not sufficient for primary isothermal crystallization especially in the core region where athermal nucleation, due to shear-induced crystallization, is largely negligible. Comparing the structures in the region near the skin with the core region at 55, 80, and $100^{\circ} \mathrm{C}$, for foils produced at $3 \mathrm{~s}$ the spherulites near the skin appear more finely distinct, which again can be explained by shear-induced nuclei during manufacturing which act as a crystallization catalyst. Nevertheless, at $120^{\circ} \mathrm{C}$ the component region near the skin seems to have a more distinct morphology with small spherulitic structures while the core area shows a mixture of large spherulites and very fine spherulitic structures. Again, it is assumed that in the component region near the skin crystallization is facilitated by shear-induced nuclei, which led to athermal and consequently faster crystallization. Within the foil's core region, where the lowest shear stresses are estimated, primary thermal nucleation is assumed. Therefore, due to the resulting slower crystallization kinetics, the component's structure is less distinct in the core region. As summarized, a significant effect of $t_{h}$ was only successfully measured at high $T_{h}$. Here, a sufficient $t_{h}$ was able to lead to the most distinct spherulitic structures while a short $t_{h}$ led to significantly less distinct inner structures.

Comparing the analytical results of the FSC and experimental results from the foil extrusion, it can be shown that during foil manufacturing crystallization effects were able to be measured even at $120^{\circ} \mathrm{C}$. With regard to the FSC measurements no isothermal crystallization was able to be measured even at $180 \mathrm{~s}$. Here, it is assumed that during the process a significant influence from athermal nucleation sped up the crystallization kinetics, which has to be considered during manufacturing.

Degree of Crystallization. Figure 11 shows the degree of crystallization $X$ for the different isothermal holding temperatures and isothermal holding times. Regarding the effect of $T_{h}$ for both isothermal holding times an increase in the degree of crystallization was able to be measured for foils produced at 55,80 , and $100^{\circ} \mathrm{C}$. Here, for an isothermal holding time of $3 \mathrm{~s}$ the degrees of crystallization reach higher values, which could be explained by the higher athermal nucleation due to higher shear stresses during manufacturing. The increase in $X$ with an increasing $T_{h}$ could be explained by the more perfectly formed inner structures. In this context, it is known that crystalline structures that have formed at higher temperatures can crystallize more perfectly, which also leads to a higher degree of crystallization. Nevertheless, at a $T_{h}$ of $120^{\circ} \mathrm{C}$ a significant decrease in $X$ is measured for foils produced with $t_{h}$ of $3 \mathrm{~s}$. Therefore, $t_{h}$ of $3 \mathrm{~s}$ leads to less perfectly developed crystals although there is higher athermal nucleation. In contrast, foils produced at $20 \mathrm{~s}$ and $120^{\circ} \mathrm{C}$ reach the highest degree of crystallization in the produced foils. Therefore, at $120^{\circ} \mathrm{C}$ the isothermal crystallization kinetics is relatively slow and a longer $t_{h}$ is necessary to attain further gains in the specific melting enthalpy. Nevertheless, for foils produced at $20 \mathrm{~s}$ the increase in $X$ with an increasing $T_{h}$ from 100 to $120^{\circ} \mathrm{C}$ is relatively small. Here, a possible explanation could be $t_{h}$ having been too short [30].

Mechanical Properties. The results of the tensile tests are shown in Figure 12. For both the secant modulus and the yield stress, an increase in the resulting mechanical parameters was measured for $t_{h}$ of 3 and $20 \mathrm{~s}$ and $T_{h}$ of 55, 80, and $100^{\circ} \mathrm{C}$. Here, the results for the lower isothermal holding times tend to reach higher mechanical parameters, which could be explained by the more distinct crystalline structures and higher degree of crystallization due to athermal nucleation. Regarding $T_{h}$ of $120^{\circ} \mathrm{C}$ and $t_{h}$ of $20 \mathrm{~s}$ a significant further increase in the mechanical parameters was able to be measured. Nevertheless, at $120^{\circ} \mathrm{C} T_{h}$ and $3 \mathrm{~s} t_{h}$ the lowest mechanical parameters were measured, which in turn can be explained by the less distinct geometry and degree of ordered structures. Therefore, a further increase in componential properties by increasing $T_{h}$ can only be achieved by increasing $t_{h}$.

Figure 13 shows the results of the DMA measurements for the foils produced at 55 and $120^{\circ} \mathrm{C}$ with respect to the investigated $t_{h}$. Comparing the results of different $t_{h}$ at $T_{h}$ of $55^{\circ} \mathrm{C}$, analogous to the tensile tests, the samples produced at $t_{h}$ of $20 \mathrm{~s}$ reach values lower than samples produced at $t_{h}$ of $3 \mathrm{~s}$, which can be explained by the more distinct morphology and degree of crystallization. Nevertheless, the differences are relatively small, especially at temperatures above $60^{\circ} \mathrm{C}$. Therefore, $t_{h}$ does not appear to be necessary at low manufacturing temperatures. Regarding the storage modulus for $T_{h}$ of $120^{\circ} \mathrm{C}$ and $t_{h}$ of $3 \mathrm{~s}$ there is no significant improvement in the storage modulus compared to the foils produced at $55^{\circ} \mathrm{C}$. Nevertheless, with a longer $t_{h}$ of $20 \mathrm{~s}$ and, therefore, an isothermal crystallization at high temperatures a significant improvement in the storage modulus was able to be achieved even with less athermal nucleation. This can be attributed to the more distinct morphology as well as degree of crystallization.

\section{Conclusion}

Regarding the influence of various cooling velocities with respect to the resulting crystallization, FSC measurements 


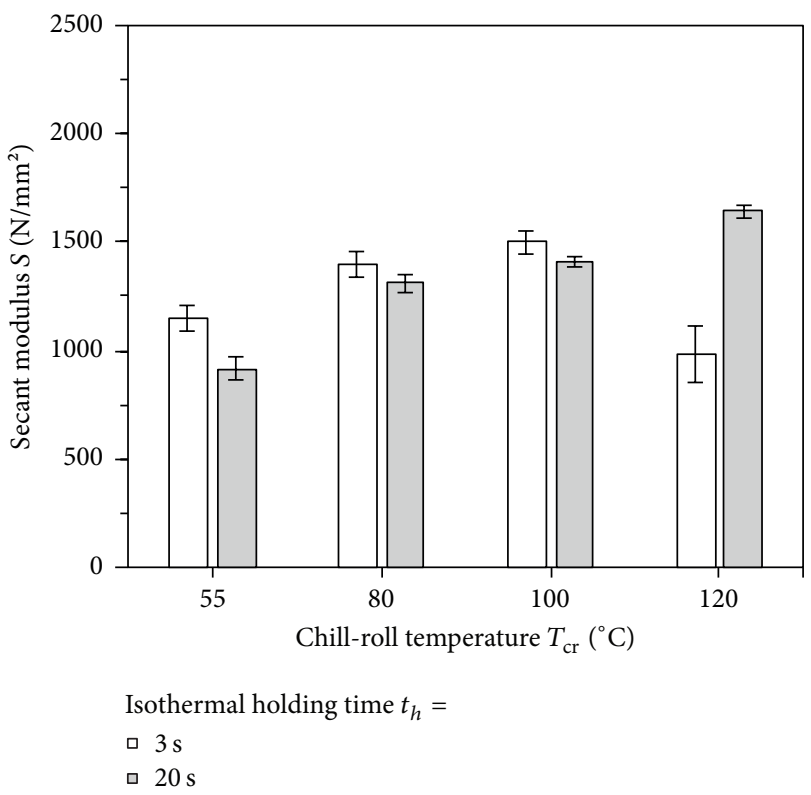

(a)

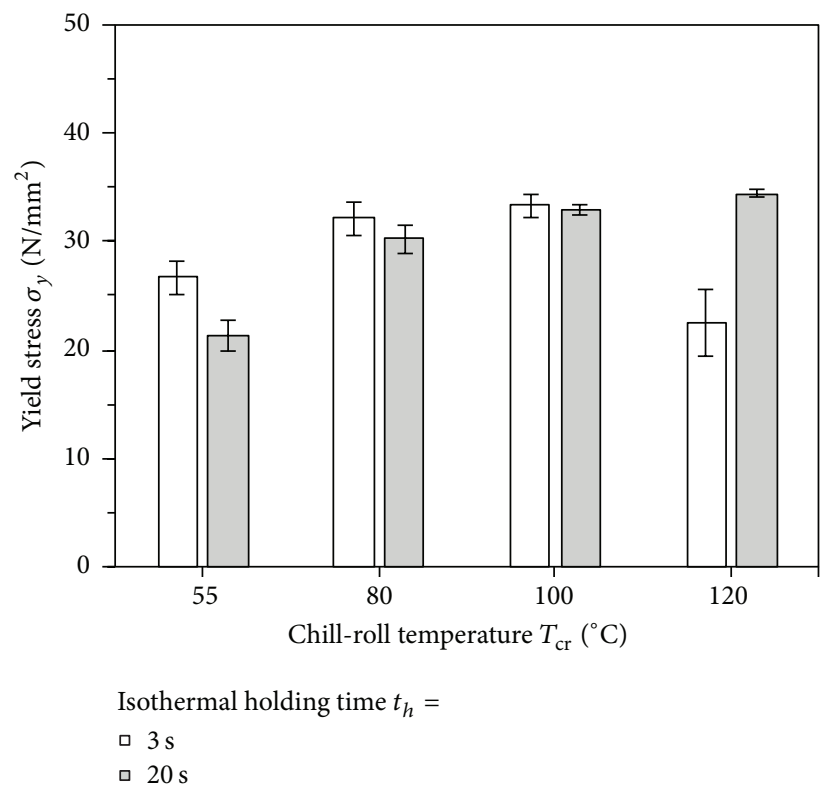

(b)

FiguRE 12: Secant modulus (a) and yield stress (b) of extruded foils manufactured at different chill-roll temperatures and isothermal holding times.

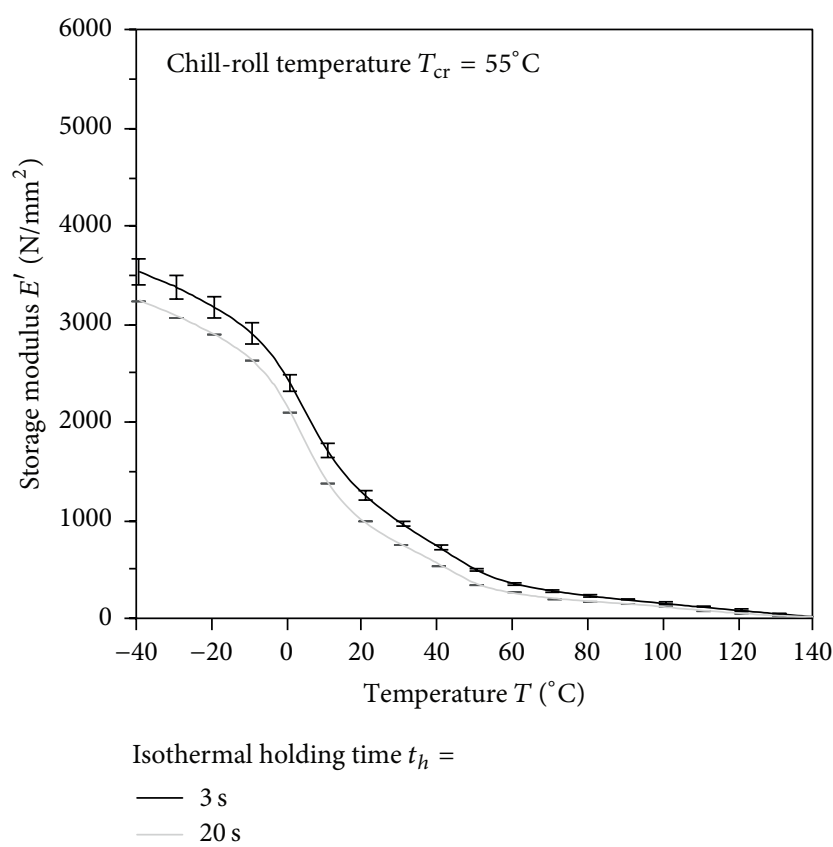

(a)

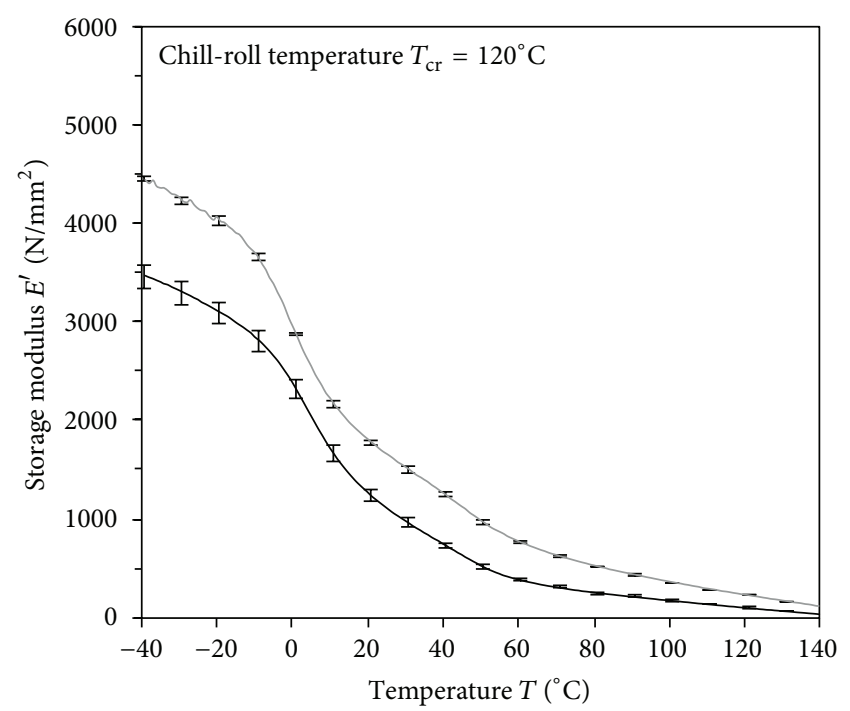

Isothermal holding time $t_{h}=$

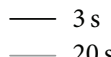

(b)

Figure 13: Storage modulus of extruded foils manufactured at chill-roll temperature of $55^{\circ} \mathrm{C} \mathrm{(a)}$ and $120^{\circ} \mathrm{C}(\mathrm{b})$.

were able to show that different crystal modifications can be achieved. Therefore, cooling velocities above $500 \mathrm{~K} / \mathrm{s}$ primarily lead to a complete vitrification of the polymer chains in the glassy state. By reducing the cooling velocity, the amount of the mesomorphic crystal phase increases in the temperature range of 10 to $40^{\circ} \mathrm{C}$. At approximately $150 \mathrm{~K} / \mathrm{s}$ it is assumed that the highest amount of mesomorphic crystal phase has developed. A further reduction in the cooling velocity leads to an increase in the monoclinic $\alpha$-phase, which is asserted to be the most stable form of isotactic polypropylene. At approximately $20 \mathrm{~K} / \mathrm{s}$ no crystallization of the mesomorphic phase was detected and the majority of the polymer chains had formed into the monoclinic $\alpha$-phase. Therefore, with a decreasing cooling velocity the polymorphs of the solid material may range from primarily amorphous to primarily mesomorphic to primary $\alpha$-monoclinic, meaning that a 
decreasing cooling velocity can lead to an increase (primarily amorphous $>v_{c}>$ primarily mesomorphic phase) as well as a decrease of the mesomorphic phase (primarily mesomorphic phase $>\quad v_{c}>$ primarily $\alpha$-monoclinic). Regarding the analytically analyzed influence of $t_{h}$ at different isothermal holding temperatures, investigations indicated that for the temperatures 60,80 , and $100^{\circ} \mathrm{C}$ an increase in $t_{h}$ can lead to an increase in the resulting melting peak temperature during the second heating. Furthermore, it was shown that with increasing temperatures the time needed for isothermal crystallization also increases, as explained by the poor thermodynamic conditions due to a lower undercooling of the melt. Consequently, at $120^{\circ} \mathrm{C}$ no isothermal crystallization was able to be measured.

Evaluating the results of the experimental setup it was shown that an increase of chill-roll temperature $\left(T_{h}\right)$ from 55 up to $100^{\circ} \mathrm{C}$ leads to a more distinct geometry and degree of ordered structures as well as an increase in the resulting mechanical parameters such as secant modulus, yield stress, and storage modulus for all investigated isothermal holding times. Further, a decrease in $t_{h}$ leads to a decrease in the spherulitic structures in the area near the skin as well as an increase in the resulting degree of crystallization, which is attributed to the higher athermal nucleation due to higher shear stresses caused by the higher rotational speed of the extruder screw. Nevertheless, the influence of $t_{h}$ seems to be less important at temperatures less than or equal to $100^{\circ} \mathrm{C}$. However, at $T_{h}$ of $120^{\circ} \mathrm{C}$ a significant effect of $t_{h}$ emerged. There, at $t_{h}$ of $20 \mathrm{~s}$ a further increase in the spherulite size and the melting enthalpy and the resulting mechanical properties were achieved as compared to the lower chillroll temperatures. However, at $t_{h}$ of $3 \mathrm{~s}$ despite the higher athermal nucleation, the lowest mechanical parameters were successfully measured. Here, it is assumed that due to the high chill-roll temperatures and the resulting slow crystallization kinetics the crystallization primarily occurred during cooling and not isothermally. This leads to a poor inner structure and degree of crystallization as well as poor resulting mechanical properties. Therefore, $t_{h}$ has to be taken into account especially at higher chill-roll temperatures.

In future work, the FSC measurements should be taken by varying the sample mass to verify the results. Here, the sample mass and, therefore, the melting enthalpy should also be calculated by means of a comparison between DSC and FSC measurements. Doing so could thus facilitate comparing quantitative results. Furthermore, aside from iPP, other semicrystalline materials should be investigated. Finally, transferring the knowledge gained through this research to the injection molding process by considering further influences on the crystallization such as pressure and shear should be a central focus of future endeavors. Here, the possibility of investigating the first heating of an injection molded sample section with the FSC could give an indication of local cooling conditions during the injection molding process.

\section{Competing Interests}

The authors declare that there is no conflict of interests regarding the publication of this paper.

\section{Acknowledgments}

The authors thank the German Research Foundation (DFG) for funding this work within Project JU 2944/1-1. The authors are also grateful to the company SABIC for providing the material.

\section{References}

[1] G. Menges, E. Haberstroh, W. Michaeli, and E. Schmachtenberg, Werkstoffkunde Kunststoffe, Hanser, München, Germany, 2011.

[2] G. W. Ehrenstein, Polymer-Werkstoffe: Struktur-EigenschaftenAnwendungen, Hanser, München, Germany, 2011.

[3] E. Piorkowska and G. C. Rutledge, Handbook of Polymer Crystallization, John Wiley \& Sons, New Jersey, NJ, USA, 2013.

[4] A. Jungmeier, G. W. Ehrenstein, and D. Drummer, "New aspects of process induced properties of microinjection moulded parts," Plastics, Rubber and Composites, vol. 39, no. 7, pp. 308-314, 2010.

[5] A. Jungmeier, I. Kühnert, G. W. Ehrenstein, and T. A. Osswald, "Process-induced properties of micro injection molded partsnew aspects," in Proceedings of the SPE Annual Technical Conference (ANTEC '09), pp. 1328-1332, Chicago, Ill, USA, 2009.

[6] B. G. Millar, P. Douglas, W. R. Murphy, and G. M. Mc Nally, "The effect of cooling regime on the thermal, mechanical and morphological properties of polyolefins," in Proceedings of the SPE Proceedings ANTEC, pp. 2258-2262, Boston, Mass, USA, 2005.

[7] I. Kolesov, D. Mileva, R. Androsch, and C. Schick, "Structure formation of polyamide 6 from the glassy state by fast scanning chip calorimetry," Polymer, vol. 52, no. 22, pp. 5156-5165, 2011.

[8] M. Van Drongelen, T. Meijer-Vissers, D. Cavallo, G. Portale, G. V. Poel, and R. Androsch, "Microfocus wide-angle X-ray scattering of polymers crystallized in a fast scanning chip calorimeter," Thermochimica Acta, vol. 563, pp. 33-37, 2013.

[9] M. Ito, K. Mizuochi, and T. Kanamoto, "Effects of crystalline forms on the deformation behaviour of nylon-6," Polymer, vol. 39, no. 19, pp. 4593-4598, 1998.

[10] C. Ramesh, "Crystalline transitions in Nylon 12," Macromolecules, vol. 32, no. 17, pp. 5704-5706, 1999.

[11] I. Kolesov, D. Mileva, and R. Androsch, "Mechanical behavior and optical transparency of polyamide 6 of different morphology formed by variation of the pathway of crystallization," Polymer Bulletin, vol. 71, no. 3, pp. 581-593, 2014.

[12] J. E. K. Schawe, "Analysis of non-isothermal crystallization during cooling and reorganization during heating of isotactic polypropylene by fast scanning DSC," Thermochimica Acta, vol. 603, pp. 85-93, 2015.

[13] S. Brückner, S. V. Meille, V. Petraccone, and B. Pirozzi, "Polymorphism in isotactic polypropylene," Progress in Polymer Science, vol. 16, no. 2-3, pp. 361-404, 1991.

[14] R. H. Somani, B. S. Hsiao, A. Nogales, H. Fruitwala, S. Srinivas, and A. H. Tsou, "Structure development during shear flow induced crystallization of i-PP: in situ wide-angle X-ray diffraction study," Macromolecules, vol. 34, no. 17, pp. 59025909, 2001.

[15] H. Huo, S. Jiang, L. An, and J. Feng, "Influence of shear on crystallization behavior of the $\beta$ phase in isotactic polypropylene with $\beta$-nucleating agent," Macromolecules, vol. 37, no. 7, pp. 2478-2483, 2004. 
[16] J. A. Sauer and K. D. Pae, "Structure and thermal behavior of pressure-crystallized polypropylene," Journal of Applied Physics, vol. 39, no. 11, pp. 4959-4968, 1968.

[17] C. Silvestre, S. Cimmino, D. Duraccio, and C. Schick, "Isothermal crystallization of isotactic poly(propylene) studied by superfast calorimetry," Macromolecular Rapid Communications, vol. 28, no. 7, pp. 875-881, 2007.

[18] V. Brucato, Z. Kiflie, V. La Carrubba, and S. Piccarolo, "The continuous cooling transformation (CCT) as a flexible tool to investigate polymer crystallization under processing conditions," Advances in Polymer Technology, vol. 28, no. 2, pp. 86-119, 2009.

[19] V. Brucato, S. Piccarolo, and V. La Carrubba, "An experimental methodology to study polymer crystallization under processing conditions. The influence of high cooling rates," Chemical Engineering Science, vol. 57, no. 19, pp. 4129-4143, 2002.

[20] S. Piccarolo, M. Saiu, V. Brucato, and G. Titomanlio, "Crystallization of polymer melts under fast cooling. II. High-purity iPP," Journal of Applied Polymer Science, vol. 46, no. 4, pp. 625634, 1992.

[21] S. Piccarolo, "Morphological changes in isotactic polypropylene as a function of cooling rate," Journal of Macromolecular Science-Part B, vol. 31, pp. 501-511, 1992.

[22] R. Androsch, M. L. Di Lorenzo, C. Schick, and B. Wunderlich, "Mesophases in polyethylene, polypropylene, and poly(1butene)," Polymer, vol. 51, no. 21, pp. 4639-4662, 2010.

[23] F. R. Schwarzl, Polymermechanik: Struktur und Mechanisches Verhalten von Polymeren, Springer, Berlin, Germany, 1990.

[24] R. Künkel, Auswahl und optimierung von kunststoffen für tribologisch beanspruchte systeme [Ph.D. dissertation], FriedrichAlexander-Universität Erlangen-Nürnberg, Erlangen, Germany, 2005.

[25] P. K. Kennedy and R. Zheng, Flow Analysis of Injection Molds, Carl Hanser, München, Germany, 2013.

[26] A. M. Rhoades, J. L. Williams, and R. Androsch, "Crystallization kinetics of polyamide 66 at processing-relevant cooling conditions and high supercooling," Thermochimica Acta, vol. 603, pp. 103-109, 2015.

[27] C. Fischer and D. Drummer, "The influence of inner component and topographical properties on tribological parameters of injection-moulded microparts," Advances in Mechanical Engineering, vol. 6, Article ID 321674, 2014.

[28] C. Fischer, "Beeinflussung von tribologischen Eigenschaften durch dynamische Temperierung," Zeitschrift Kunststofftechnik, vol. 11, no. 2, pp. 43-68, 2015.

[29] G. W. Ehrenstein, G. Riedel, and P. Trawiel, Praxis der Thermischen Analyse von Kunststoffen, Hanser, München, Germany, 2003.

[30] Q. Zia, H.-J. Radusch, and R. Androsch, "Direct analysis of annealing of nodular crystals in isotactic polypropylene by atomic force microscopy, and its correlation with calorimetric data," Polymer, vol. 48, no. 12, pp. 3504-3511, 2007. 

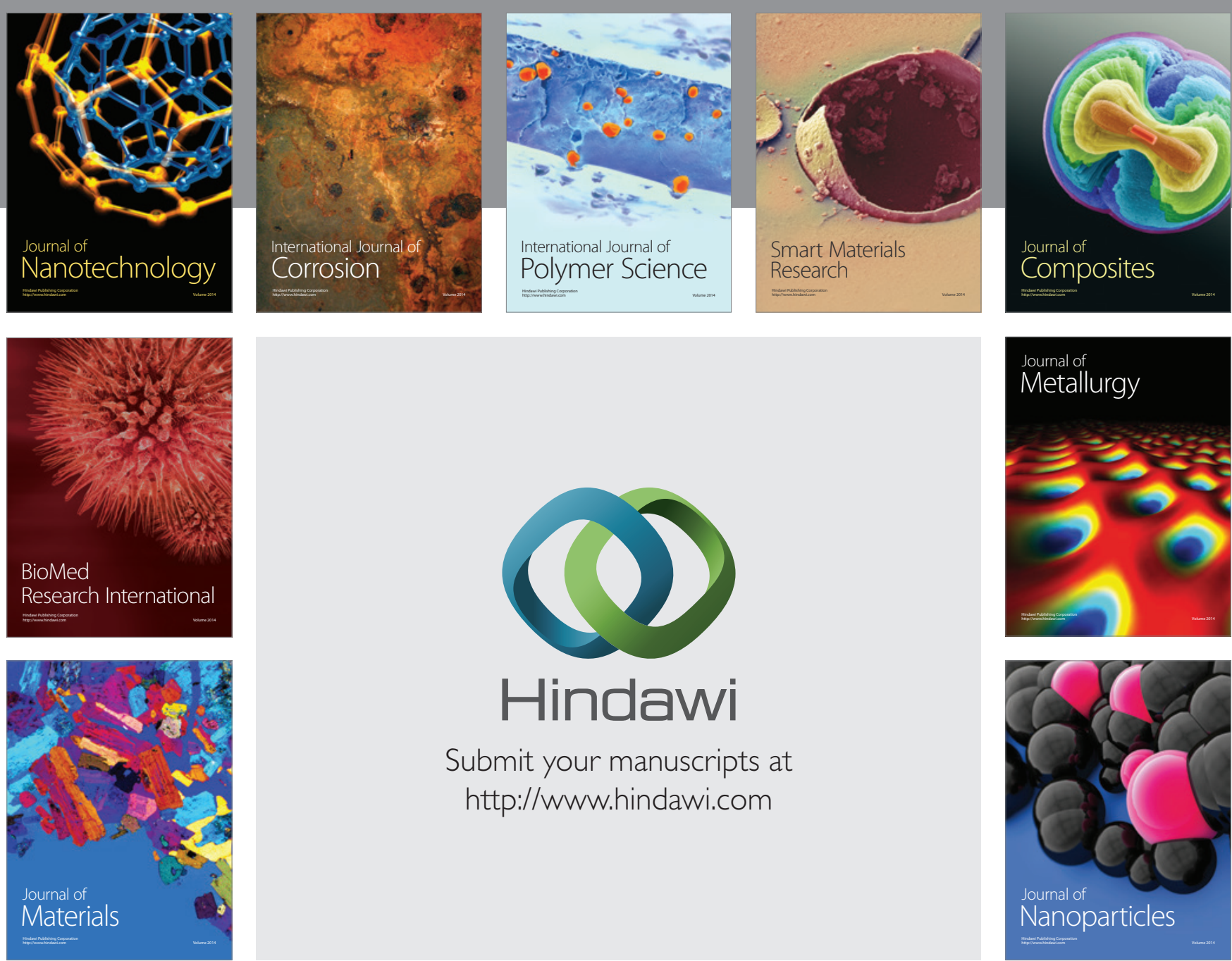

\section{Hindawi}

Submit your manuscripts at

http://www.hindawi.com

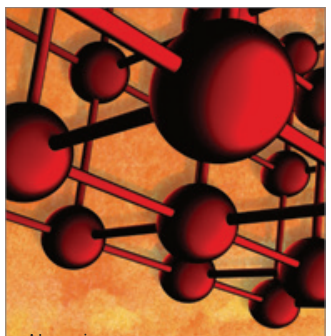

Materials Science and Engineering
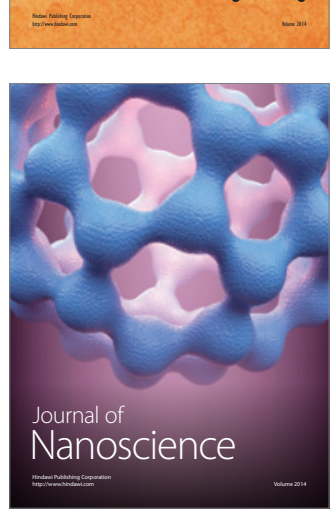
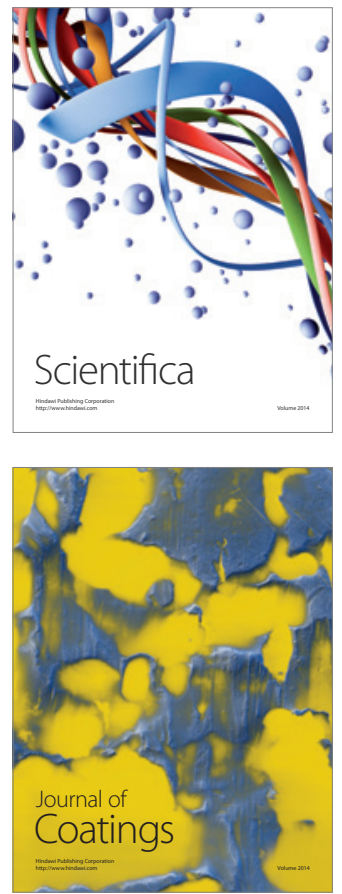
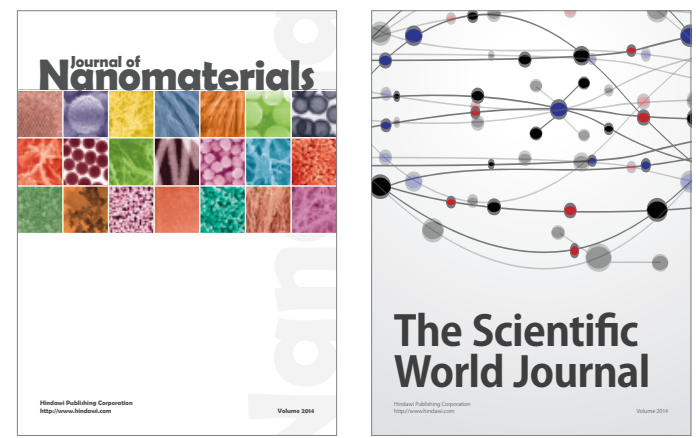

The Scientific World Journal
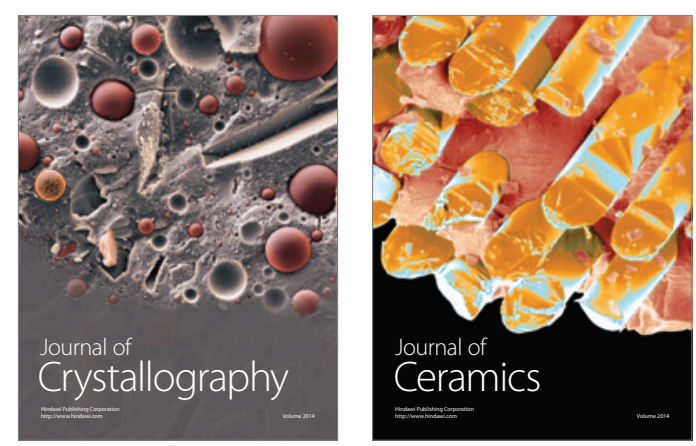
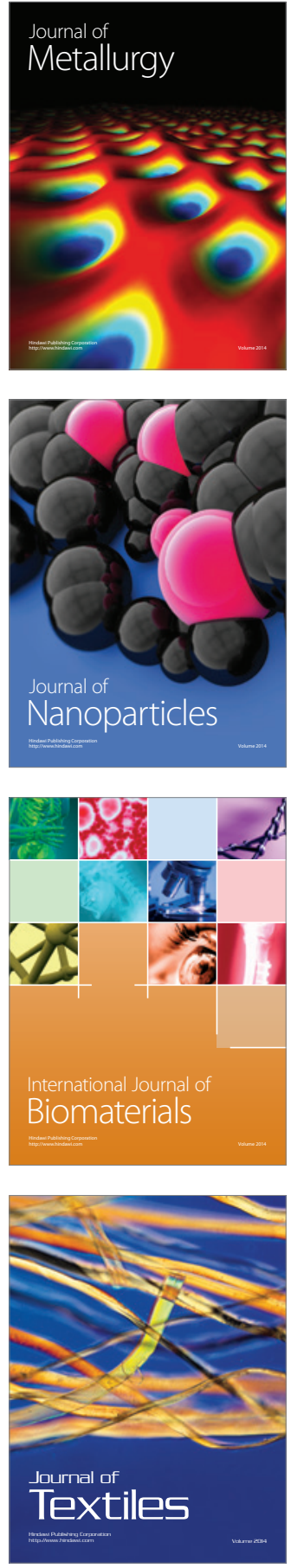